\title{
Cremilda Medina: pedagogia dos afetos na universidade
}

\author{
Cremilda Celeste de Araújo Medina \\ Universidade de São Paulo, Escola de Comunicações e Artes, Programa de Pós-Graduação em Ciências \\ da Comunicação, São Paulo, SP, Brasil \\ medinase@usp.br
}

Alex Sander Alcântara Lopes de Santana Universidade de São Paulo, Escola de Comunicações e Artes, Programa de Pós-Graduação em Ciências da Comunicação, São Paulo, SP, Brasil alexsander.alcantara@usp.br

Gean Oliveira Gonçalves Universidade de São Paulo, Escola de Comunicações e Artes, Programa de Pós-Graduação em Ciências da Comunicação, São Paulo, SP, Brasil geangoncalves@usp.br

Liana Maria Milanez Pereira Universidade de São Paulo, Escola de Comunicações e Artes, Programa de Pós-Graduação Integração da América Latina, São Paulo, SP, Brasil limilanez@gmail.com

Luiza da Silva Bodenmuller

Universidade de São Paulo, Escola de Comunicações e Artes, Programa de Pós-Graduação em Ciências da Comunicação, São Paulo, SP, Brasil luizabodenmuller@gmail.com

Sonia Regina Soares da Cunha

Universidade de São Paulo, Escola de Comunicações e Artes, Programa de Pós-Graduação em Ciências da Comunicação, São Paulo, SP, Brasil reginacunha@usp.br

DOI: https://doi.org/10.26512/rici.v13.n2.2020.30889

Recebido/Recibido/Received: 2019-12-14

Aceitado/Aceptado/Accepted: 2020-04-14

Resumo: Este artigo apresenta a experiência pedagógica de Cremilda Medina, jornalista, pesquisadora e professora titular sênior da Universidade de São Paulo (USP). Nas etapas de mais de cinco décadas, resumem-se aqui diferentes momentos da mediação social dialógica, eixo central de sua proposta pedagógica, fixado em 19 livros de autoria da pesquisadora e mais de 50 coletâneas por ela organizadas. O estudo reflexivo qualitativo combina metodologias que se complementam como o estudo de caso, pesquisa histórica documental, bibliográfica, entrevistas e observação-experiência. Entre as possibilidades afetivas da docência praticada por Cremilda Medina destaca-se o conceito de ensinoaprendizagem caracterizado pela ação, e não pela verbalização de conhecimentos.

Palavras-chave: pedagogia dos afetos. Epistemologia. diálogo social. signo da relação.

\section{Cremilda Medina: affection pedagogy in the university}

Abstract: This article presents the pedagogical experience of Cremilda Medina, journalist, researcher and senior full professor at the University of Sao Paulo (USP). In the stages of more than five decades, we summarize here different moments of dialogical social mediation, the central axis of her pedagogical 
proposal, set in 19 books by the researcher and more than 50 collections organized by her. The qualitative reflexive study combines complementary methodologies such as case study, documentary historical research, bibliographic research, interviews and observation-experience. Among the affective possibilities of teaching practiced by Cremilda Medina is the concept of teaching-learning characterized by action and not by verbalization of knowledge.

Keywords: affection pedagogy. epistemology . social dialogue. relation's sign.

\section{Cremilda Medina: pedagogía afectiva en la universidad}

Resumen: Este artículo presenta la experiencia pedagógica de Cremilda Medina, periodista, investigadora y profesora titular sénior en la Universidad de Sao Paulo (USP). En las etapas de más de cinco décadas, resumimos aquí diferentes momentos de mediación social dialógica, el eje central de su propuesta pedagógica, establecida en 19 libros por la investigadora y más de 50 colecciones organizadas por ella. El estudio reflexivo cualitativo combina metodologías complementarias como estudio de caso, investigación histórica documental, investigación bibliográfica, entrevistas y observación-experiencia. Entre las posibilidades afectivas de la enseñanza practicada por Cremilda Medina se destaca el concepto de enseñanza-aprendizaje caracterizado por la acción y no por la verbalización del conocimiento

Palabras clave: pedagogía afectiva. Epistemología. diálogo social. signo de la relación.

\section{Introdução}

\subsection{Por um cenário participativo e pleno de conhecimentos}

Como ensino recente, a formação em jornalismo no Brasil não possui uma tradição pedagógica, cuja dinâmica está marcada pela técnica expositiva e pela conformação de um saber dogmático. A opção prioritária na maioria dos cursos concentra-se no exercício da profissão de jornalista buscando simular as experiências das redações. Um complexo desafio didático enfrentado pela professora Cremilda Medina desde que iniciou sua trajetória educacional na Universidade Federal do Rio Grande do Sul (UFRGS), de 1962 a 1970, e depois a partir de 1971, na Universidade de São Paulo. Medina observa que, desde o princípio, resistia ao formato de apresentação de aulas expositivas com base nos manuais traduzidos da bibliografia americana. Para a educadora "a ausência de metodologia de ensino superior bateu de frente com o aprendizado de didática que completara na mesma universidade". (MEDINA, 2006, p. 158). Neste cenário que ainda prevalece em alguns cursos de graduação de jornalismo Medina observa duas imagens contrastantes de relações de ensino: a) o professor que expõe seu conhecimento, transplanta experiências e assimilações para o estudante que registra e acumula o saber; e b) o educando em um cenário que possibilita a articulação de conhecimentos, vive o processo de forma direta e participativa, capacitando-se para a ação.

Em síntese, o que determina o processo de ensino é a relação afetiva entre educador e educando, e não o professor expositor que centraliza a aula em si. Além da graduação em Jornalismo, Medina também obteve licenciatura em Letras na Universidade Federal do Rio Grande do Sul (UFRGS), ampliando assim a perspectiva pedagógica que migra da explicação do professor para uma compreensão interativa em grupo. É com essa base pedagógica compreensiva que Medina desenvolve seu trabalho na USP, espaço acadêmico no qual é 
incentivada a criar conhecimento e estendê-lo imediatamente à sociedade. Assim, da inconformidade com o paradigma do professor expositor que "se ilude na mesma perspectiva do jornalista difusionista", e graças aos influxos que encontra na USP, Medina passa a pesquisar a cada aula o laboratório da "interação social criadora" que advém do "signo da relação" processo que "só ocorre na interação criadora em que ambos se transformam: educadoreducando e contexto da educação, comunicador-comunidade emissora e receptora. (MEDINA, 2006, p.161).

Para Medina o professor precisa estar atento para o "momento de experimentação" do aluno para que a fala cheia de erudição não soe vazia de significados. Quando ocorre a interação os educandos são afetivamente marcados pelo resultado palpável das dinâmicas e objetivos construídos em grupo. É essa experiência de comunhão dos significados da contemporaneidade que Medina nomeia de laboratorial, ou seja, momento de partilhar a escuta, comprometer-se com saberes multidisciplinares e ousar a própria autoria do conhecimento. É por meio dessa visão pedagógica afetiva que Cremilda Medina, uma das pesquisadoras brasileiras em jornalismo com maior contribuição teórica compartilha seu legado epistemológico entre gerações.

\section{Por uma epistemologia dos sentidos}

Os estudos sobre o jornalismo liderados por Medina, tanto no Brasil quanto no exterior, são um divisor de águas na produção acadêmica desde anos de 1960. Suas análises tornam-se referências na área a partir do clássico Notícia um produto à venda jornalismo na sociedade urbana e industrial (Alfa-Ômega, 1978), obra resultante da dissertação de Mestrado e que sedimenta um dos primeiros estudos sobre jornalismo interpretativo no Brasil.

Toda a produção autoral - e para Medina autoria assume uma dimensão central nas obras acadêmicas e nas reportagens - revela a dimensão simbólica de sentidos na qual comunga a união entre ética, técnica e estética, mediadas por diversas formas de conhecimento. Entre os inúmeros eixos temáticos de suas pesquisas ao longo de décadas, Medina observa a relação entre Jornalismo, Ciência e Arte. Ao elaborar os diagnósticos epistemológicos sobre a atividade jornalística a partir da ideia de produção cultural Medina observa com clareza as atrofias e reducionismos da produção jornalística como uma herança persistente do positivismo a dominar as ciências no século XIX e que conduzem a atividade jornalística contemporânea.

No ensaio Jornalismo e a epistemologia da complexidade (MEDINA, 1991), a autora observa a relação da atividade jornalística com a ciência e a cultura, sinalizando a ausência de uma mentalidade abrangente dos profissionais da comunicação no processo de produção de significados. No que diz respeito à produção simbólica, os profissionais da imprensa 
normalmente mantém a "tipificação" das manifestações artísticas em cultura de elite, massa e popular. Essa perspectiva de atuação leva o jornalista a se tornar um divulgador de conhecimentos, e não num produtor cultural de sentidos. Medina observa que, para romper com o paradigma de jornalista-divulgador o profissional deve ampliar a visão autoral e refletir compreensivamente sobre os desafios epistemológicos da formação e da prática jornalística, entre eles: a) responsabilidade social nas mediações do jornalista; b) pesquisa da narrativa cúmplice com a polifonia; c) visão de mundo e atitude abertas à complexidade racional, à sensibilidade intuitiva e à estética inovadora; d) intercâmbio interdisciplinar com outras áreas de conhecimento no contexto de paradigmas em crise; e e) construção de novas noções para operar o diálogo social.

\section{Por uma inteligência complexa, sensível e inovadora}

De oficinas pedagógicas nas universidades brasileiras e no exterior resulta a defesa do autor da "assinatura coletiva" presente nas Narrativas da Contemporaneidade (da comunicação social). No livro $A$ arte de tecer o presente (Summus, 2003) a autora escreve que a narrativa expressa a necessidade de reagir ao caos da história, criando um cosmo simbólico. O que mobiliza a produção cultural, ou seja, a autoria da narrativa organiza e atribui significados ao acontecer cotidiano ou aos fatos extraordinários. Ideias, comportamentos, ação coletiva compõem a cena simbólica da narrativa. Medina $(2016$, p. 7) observa que ao sentir com a inteligência plena "em presença, pela racionalidade ética, a técnica competente e a estética transformadora", o autor possibilita a criação de um ou vários narradores que desempenham a pluralidade de protagonistas da circunstância humana.

A estilística que produz sentidos é uma combinação de histórias de vida (protagonismo), racionalidade complexa para armar nexos da experiência coletiva (contextos sociais), ensaísmo multidisciplinar conjugando vozes históricas e antropológicas (raízes histórico-culturais) e entrevistas especializadas (diagnósticos e prognósticos). (MEDINA, 2003). Essas vertentes epistemológicas formam a essência da "mediação social dialógica" desenvolvida há quase seis décadas nos laboratórios coordenados por Medina na graduação, pós-graduação e terceira idade, tanto na USP quanto em outras universidades do Brasil e do exterior. Para compor a "autoria coletiva" deste artigo contamos com as reflexões compreensivas de ex-orientandos da professora Cremilda Medina.

\section{Com a palavra os educandos da pedagogia dos afetos}

\subsection{Márcia Blasques: de nau dos desejos a navegar é preciso}


A experiência laboratorial de produção de textos para os livros-reportagem Guia da Almas (1993, v. 13) e Nau dos desejos (1994, v. 14) marcou a trajetória acadêmica da estudante de jornalismo Márcia Aparecida Silva Blasques. Os livros foram organizados pela professora Cremilda Medina e fazem parte da coleção São Paulo de Perfil editada e publicada pela ECAUSP. Para Blasques (2016, p. 88) aqueles textos representaram suas "primeiras experiências reais na grande reportagem, no mergulho na alteridade que marca a alma do jornalista". A caminhada feita de laços de "respeito e admiração aluna-professora", levou Blasques a cursar o mestrado sob orientação de Medina, cujo resultado foi a dissertação Jornalismo e Ciência: tecendo propostas para um diálogo possível (BLASQUES, 2005), onde a autora reflete sobre o jornalismo científico e a relação dos jornalistas com a crise de paradigmas da Ciência e com a crise de paradigmas do próprio Jornalismo. Um desdobramento coerente com tudo o que Blasques estudou e praticou nos laboratórios coordenados por Cremilda Medina. No doutorado Blasques avança na "pedagogia dos afetos" ao defender a tese Navegar é preciso: jornalismo, autoria e colaboração (2010) onde percorre o viés da criação colaborativa na web 2.0, refletindo sobre os laços entre o jornalismo e a sociedade. A autoria aparece no centro da investigação científica de Blasques, observando a

\begin{abstract}
premissa de que o jornalismo é, antes de mais nada, um mediador social e um narrador da atualidade. E a pergunta para a qual procurarei uma resposta - provavelmente o mais correto seria dizer 'pistas' - é: o jornalista continua autor de seu trabalho, considerando as possibilidades de interação e criação colaborativa proporcionadas pela web 2.0? É possível falar em 'autoria' - e, se sim, qual sua relevância - num mundo em que qualquer pessoa pode publicar o que quiser na rede? (BLASQUES, 2010, p. 9).
\end{abstract}

Atualmente a jornalista Doutora Márcia Blasques é diretora da Divisão de Informação, Documentação e Serviços Online da Superintendência de Comunicação Social da USP e responsável pelo Portal da USP e pela Agência USP de Notícias.

\title{
4.2. Angelo Ishi: versão oriental da pedagogia dos afetos
}

"Foi um encontro decisivo e transformador, nos anos 1980" observa Ishi, que batizou o momento de ichigo-ichie. "Na época, eu pensava que tinha aprendido com Cremilda como ser um bom jornalista. Hoje, percebo que ela foi, ao mesmo tempo, uma referência de bom professor". (ISHI, 2016, p. 121). Para além dos ensinamentos sobre a técnica e a ética, Ishi destaca o convívio inspirador para a vida, como jornalista e professor:

Um dos provérbios mais apreciados pelos japoneses tem apenas quatro ideogramas e se lê "ichigo-ichie" (一期一会). Significa um encontro único, insubstituível. Nos dicionários, costuma-se traduzi-lo como "oportunidade única na vida", "valorize cada encontro porque ele poderá nunca mais se repetir. Penso que meu encontro com Cremilda 
Medina, nos anos 1980, foi do gênero "ichigo-ichie". (ISHI, 2016, p. 121).

Um texto de Ishi publicado em setembro de 1987 no Jornal do Campus faz parte da gramática do grupo de estudos e das disciplinas desenvolvidas por Cremilda Medina. A reportagem Memórias póstumas de um estudante de Medicina (1987) traz em si a marca da autoria ousada. Nela, Ishi narra a carta-testamento do suicídio do então aluno de Medicina, Pedro Bezerra Arantes. Ao conversar com amigos, familiares, professores e colegas de turma, Ishi reconstitui um complexo mosaico e tenta compreender o que levou o estudante de Medicina da USP a cometer o ato extremo. A reportagem em tom testemunhal desvenda as dificuldades daqueles que frequentam a Faculdade de Medicina e as disputas internas às quais são submetidos. Um dos pontos levantados por Ishi é o método pedagógico falho, que não dá conta de acolher estudantes mais sensíveis e promove uma espécie de embrutecimento, a perda de sensibilidade dos futuros médicos, quando na verdade, deveria privilegiar a formação humanista.

Sobre a "pedagogia dos afetos" praticada por Cremilda Medina, Ishi observa que são ensinamentos que estimulam o campo da sensibilidade. Para além das aulas sobre a técnica Ishi relembra que havia um grande encontro entre jornalismo, ficção, literatura, sociologia, artes e outras áreas do saber e do sentir que auxiliam o jornalista no papel de mediador e produtor cultural. Ensinamentos que Ishi levou na bagagem para o Japão onde é professor titular da Faculdade de Sociologia da Musashi University.

Como a "pedagogia dos afetos" tem em si uma abordagem pedagógica que rompe com o paradigma do professor-expositor, a prática do professor Ishi provoca estranheza em seus colegas: "Há professores que ficam pasmos quando digo que gastei 180 minutos (dois módulos de 90 minutos) fazendo brainstorming [dinâmica de grupo] com os alunos para buscar o título ideal do caderno que compila os artigos dos meus orientandos" (ISHI, 2016, p. 122).

O que importa realmente, observa Ishi, é que o investimento na "pedagogia dos afetos" traz recompensas e os alunos inserem na prática o que é vivenciado em sala de aula, passando por leads cinematográficos até a decisão de não entrevistar vítimas da tragédia após o terremoto seguido de tsunami que atingiu o Japão em 2011. Ao desenvolver a "pedagogia dos afetos" o professor Doutor Ishi faz valer o ichigo-íchie ofertado pela professora Cremilda Medina há mais de três décadas.

\subsection{Katiuscia Fogaça: a cura pelo afeto}


No começo do século XXI, a jovem estudante de jornalismo Katiuscia Fogaça, brinda o público com a reportagem-ensaio Amor o melhor remédio, para o livro Sagas do Espigão (2002, v. 24), que reportava a vivência cotidiana dos protagonistas dos espaços sagrados da Faculdade de Medicina da Universidade de São Paulo. Quem conta a saga da talentosa jornalista é a orientadora Cremilda Medina (2019, p. 115):

Katiuscia Fogaça defendeu o trabalho de conclusão, o mestrado e o
doutorado em Ciências da Comunicação com reconhecidos méritos das
bancas, orgulho de sua família e de meu grupo de pesquisa por sua integração
sensível e rigorosa. [...] Ousada guerreira, casou, se deslocou com o
companheiro para Cascavel, no Paraná, e, após breve trabalho na
comunicação social e na docência universitária, deu uma guinada e fez
vestibular para medicina. Ou seja, agora a professora doutora pela
Universidade de São Paulo é outra vez doutora Katiuscia, médica.

Alguém poderia então perguntar se a pedagogia não deu certo? Fogaça (2019) garante que foi o lado ecano das aulas com Medina que a ajudou a realizar uma revolução acadêmica no curso de Medicina, em especial diante da teoria telomérica da finitude do organismo, em outras palavras, Fogaça usa a vivacidade e inquietude da "pedagogia dos afetos" para mostrar à fisiologia que não há um fim tosco e melancólico para a humanidade. Assim, Fogaça assume a tarefa de frutificar a comunicação social através de outras vertentes comunicacionais como observa Medina (2016, p. 103): "um fruto nem sempre se desprende da árvore e é consumido in natura: há a possibilidade de prolongar seu desfrute, processando-o ou germinando-o". No caso da semente Katiuscia Fogaça o resultado promove a hibridação afetiva entre as áreas de Comunicação e Medicina. E essa hibridação pode ser observada nos encontros acadêmicos coordenados por Medina onde também é possível vivenciar a interdisciplinaridade plural e polifônica que faz a efervescência dos diálogos entre os protagonistas alunos e/ou professores, engenheiros, psicólogos, médicos, publicitários, jornalistas, enfim. Porque, ao contrário da visão objetivista, Cremilda Medina recupera a noção de sujeito na epistemologia das mediações sociais.

\section{Com a palavra Cremilda Medina, educadora-educanda}

Nesta última parte do artigo a assinatura autoral é da própria professora Cremilda Medina.

Os depoimentos aqui reunidos, a essa altura da vida, gratificam a utopia inspiradora da noção que assimilei de professores que já se foram: a interação social criadora. Tanto no exercício profissional do jornalismo (passei por diversas mídias do mercado), quanto na sala de aula (do rápido exercício de magistério no segundo grau nos anos 1960 à docência universitária, 
a partir de 1967) persegui o diálogo possível na arte de tecer o presente e na experiência de ensino-aprendizagem.

Ao participar como responsável pela comunicação social em um Congresso de Ensino de Medicina, na Universidade Federal do Rio Grande do Sul (UFRGS), em fins dos anos 1960, pude apreender que os problemas da didática de ensino superior atravessam grande parte das áreas de conhecimento. Desde então venho trazendo esse debate para a área de Ciências da Comunicação e, em particular, para o Jornalismo. Foi assim que propus um seminário no CIESPAL, Quito, Equador, na década seguinte e levantei o tema junto a professores universitários da América Latina. Nos anos 1980, foi a vez Universidade Federal de Santa Maria (UFSM) me chamar para trabalhar com essa carência. E ainda nessa época organizei no Departamento de Jornalismo da ECA-USP, em São Paulo, um encontro com o propósito de refletir sobre a pedagogia aplicada ao ensino superior de jornalismo.

Para além do discurso de tais propósitos, aprendi, lá no horizonte da formação inaugural, que três eixos fundantes regem a mutação de ensino para a experiência de ensinoaprendizagem. E são esses os focos recorrentes do planejamento didático na universidade ou em qualquer grau de escolaridade:

a) Atuar perante cada educando como um sujeito particular e não um objeto de resultados programáticos;

b) Desenvolver a atividade em laboratório em que educador e educando aprendem e se transformam a partir do conhecimento acumulado;

c) Culminar com o cruzamento fértil do EU e do COLETIVO, passível de ser especulado no contato vivo, presencial, no trânsito externo à academia e à sala de aula.

Desse mergulho na realidade, tenho me maravilhado com a produção de alunos de graduação e pós-graduação. Como autores originais no rigor científico, sensíveis às demandas sociais e transformadores das visões autoritárias para as práticas democráticas, produzem narrativas como as da série São Paulo de Perfil, do Novo Pacto da Ciência no Projeto Plural, em outras coleções da USP, obras editadas em universidades nacionais e fora do Brasil.

Jornalistas, advogados, médicos, agrônomos ou alunos/orientandos de várias áreas de conhecimento, como profissionais de mercado ou de instituições acadêmicas atestam a teoria/prática que ensaiei registrar no capítulo Caderno de anotações didáticas do livro O signo da relação, comunicação e pedagogia dos afetos (Paulus, 2006), onde proponho alguns quadros sinópticos, dos quais destaco: "na aprendizagem ocorre uma transformação interior e profunda, que se processa em experiências pessoais e diretas com a realidade; na pseudo-aprendizagem ocorrem mudanças superficiais, acumulam-se conhecimentos fáceis de adquirir e fáceis de abandonar". (MEDINA, 2006, p. 169). Aos autores do presente ensaio, minha gratidão por reacenderem esta devoção ao Outro e a sua circunstância. 


\section{Referências}

BLASQUES, Marcia. Jornalismo e ciência: tecendo propostas para um diálogo possível. Dissertação. (Mestrado em Ciências da Comunicação) .Escola de Comunicações e Arte da USP, São Paulo, 2005.

BLASQUES, Marcia. Navegar é preciso: Jornalismo, autoria e colaboração. Tese. (Doutorado em Ciências da Comunicação). Escola de Comunicações e Artes da USP, São Paulo, 2010.

BLASQUES, Marcia. Diálogo dos afetos. In: MEDINA, C. Ato Presencial: mistério e transformação. São Paulo: Casa da Serra, 2016. p. 85-98.

FOGAÇA, Katiuscia C.L. A árvore frondosa de dourados frutos. In: MEDINA, C. Ato Presencial: mistério e transformação. São Paulo: Casa da Serra, 2016. p. 103-109.

FOGAÇA, Katiuscia C.L. A vida é apenas um passatempo, até o tempo passar. In: MEDINA, C. (org.). Reproposta para todas as idades. São Paulo: ECA-USP, 2019.

ISHI, Angelo. Memórias póstumas de um estudante da Medicina. In: Jornal do Campus de 14/09/1987, São Paulo: CJE ECA-USP, 1987. p. 7.

ISHI, Angelo. "Ichigo-ichie", a presença insubstituível. In: MEDINA, C. Ato Presencial: mistério e transformação. São Paulo: Casa da Serra, 2016. p.121-123.

MEDINA, Cremilda. Notícia: um produto à venda: jornalismo na sociedade urbana e industrial. São Paulo: Alfa-Ômega, 1987.

MEDINA, Cremilda. Jornalismo e a epistemologia da complexidade. In: MEDINA, C. (org.) Novo Pacto da Ciência, I Seminário Transdisciplinar: A crise de paradigmas. Anais. São Paulo: ECA/USP, 1991.

MEDINA, Cremilda. (org.). Guia das Almas. São Paulo: ECA/USP, 1993. (Coleção São Paulo de Perfi, v. 13).

MEDINA, Cremilda. (org.). Nau dos desejos. São Paulo: ECA/USP, 1994. (Coleção São Paulo de Perfil, v. 14).

MEDINA, Cremilda. (org.). Sagas do Espigão, 90 anos de medicina e vida. São Paulo: ECA/USP, 2002. (Coleção São Paulo de Perfil, v. 24).

MEDINA, Cremilda. A arte de tecer o presente: narrativa e cotidiano. São Paulo: Summus, 2003.

MEDINA, Cremilda. $O$ signo da relação: comunicação e pedagogia dos afetos. São Paulo: Paulus, 2006.

MEDINA, Cremilda. Ato Presencial: mistério e transformação. São Paulo: Casa da Serra, 2016. 